\title{
Development of a Biomass Assessment Method Using Fisheries Echo Sounder for Monitoring Whitebait Fishery in Shizuoka Prefecture, Japan
}

Kenichi Kobayashi

Shizuoka Prefectural Marine Technology, Research Institute, Japan

Yanhui Zhu

Graduate School of Environmental Science, Hokkaido University, Japan, zhuyanhui0817@eis.hokudai.ac.jp

Daichi Oshiyama

Graduate School of Environmental Science, Hokkaido University, Japan

Kenji Minami

Estuary Research Center, Shimane University, Japan

Hokuto Shirakawa

Japan Sea National Fisheries Research Institute, Japan Fisheries Research and Education Agency, Japan

See next page for additional authors

Follow this and additional works at: https://jmstt.ntou.edu.tw/journal

Part of the Fresh Water Studies Commons, Marine Biology Commons, Ocean Engineering Commons, Oceanography Commons, and the Other Oceanography and Atmospheric Sciences and Meteorology Commons

\section{Recommended Citation}

Kobayashi, Kenichi; Zhu, Yanhui; Oshiyama, Daichi; Minami, Kenji; Shirakawa, Hokuto; and Miyashita, Kazushi (2021) "Development of a Biomass Assessment Method Using Fisheries Echo Sounder for Monitoring Whitebait Fishery in Shizuoka Prefecture, Japan," Journal of Marine Science and Technology. Vol. 29: Iss. 2, Article 5.

DOI: $10.51400 / 2709-6998.1078$

Available at: https://jmstt.ntou.edu.tw/journal/vol29/iss2/5

This Research Article is brought to you for free and open access by Journal of Marine Science and Technology. It has been accepted for inclusion in Journal of Marine Science and Technology by an authorized editor of Journal of Marine Science and Technology. 
Development of a Biomass Assessment Method Using Fisheries Echo Sounder for Monitoring Whitebait Fishery in Shizuoka Prefecture, Japan

\section{Authors}

Kenichi Kobayashi, Yanhui Zhu, Daichi Oshiyama, Kenji Minami, Hokuto Shirakawa, and Kazushi Miyashita 


\title{
Development of a Biomass Assessment Method Using Fisheries Echo Sounder for Monitoring Whitebait Fishery in Shizuoka Prefecture, Japan
}

\author{
Kenichi Kobayashi ${ }^{a}$, Yanhui Zhu ${ }^{\text {b,* }}$, Daichi Oshiyama ${ }^{\text {b }}$, Kenji Minami ${ }^{c}$, \\ Hokuto Shirakawa ${ }^{d}$, Kazushi Miyashita ${ }^{e}$ \\ a Shizuoka Prefectural Marine Technology, Research Institute, Japan \\ ${ }^{\mathrm{b}}$ Graduate School of Environmental Science, Hokkaido University, Japan \\ ${ }^{\mathrm{c}}$ Estuary Research Center, Shimane University, Japan \\ d Japan Sea National Fisheries Research Institute, Japan Fisheries Research and Education Agency, Japan \\ e Field Science Center for Northern Biosphere, Hokkaido University, Japan
}

\begin{abstract}
Coastal fisheries constitute the second most important sector in fishery production in Japan, following offshore fisheries. Thus, spatial evaluation of coastal fishing grounds and understanding of the changes in biomass are important for the sustainable use of fishing resources. For the assessment of spatial fish biomass, a quantitative echo sounder is used, but such a device is not mass produced and involves a high cost. In the present study, we examined the feasibility of biomass assessment using typical commercial fisheries echo sounders that are widely used and cheaper than quantitative echo sounders. Therefore, we aimed to verify the validity of biomass calculations using a fisheries echo sounder and examine the relationship between the cross-sectional distribution of fish schools calculated from a fisheries echo sounder and the biomass obtained from a quantitative echo sounder. As a case study, we selected the whitebait fisheries in Mochimune, Suruga Ward, Shizuoka City, in the Shizuoka Prefecture. In addition, we designed a system in which the distribution information of fish schools (fish school map) based on data obtained from the fisheries echo sounder and positional information is shared only with data providers (fishery workers). Fishery workers refer to this information and make decisions on their operations and fishing grounds. We hope to further enhance the system by, improving the cost effectiveness ratio of necessary cost for fisheries to the catch price.
\end{abstract}

Keywords: Fisheries echo sounder, Quantitative echo sounder, Rapid notification system

\section{Introduction}

$\mathrm{C}$ oastal fisheries are an important type of fisheries in Japan, employing $59 \%$ of fishery workers and contributing to $30 \%$ of the total annual marine fishery production (White paper on fisheries, 2011). The production of coastal fisheries peaked at 2.27 million tons in 1985, but it has been declining since then, plummeting to
990,000 tons in 2016 [11]. For stagnant coastal fisheries, maximizing the sustainable use of resources is necessary. Thus, the resources must be evaluated, and their biomass must be appropriately determined [6]. However, at present, most surveys have only been conducted by government and academic ships; hence, the area coverage and number of surveys have been insufficient [3]. In addition, information on 
marine conditions and resources are not usually shared among fishery workers through an organized system [18].

Despite this circumstance, there is a whitebait fishery business in Mochimune, Suruga Ward in Shizuoka Prefecture where fishery workers are obtaining data on their own and sharing such data among themselves [8]. Whitebait fishery is popular along the shoreline of the Pacific Ocean, specifically Osaka Bay, the Kii Channel, and Suruga Bay being the major whitebait fishing grounds [7]. Whitebait is a collective term for late-stage larvae [23], when the body is still transparent, or slightly older immature fry of Clupeiformes, typically between two weeks and two months in age [4]. Whitebaits are not strong swimmers and are strongly influenced by the marine environment and currents [2]. The whitebait fishery in the Shizuoka Prefecture is operated from Enshunada to the shores of the Suruga Bay. The annual production is 7000 tons and the production value ranges from around four to five billion yen [2]. The whitebait fishery in Mochimune, which we surveyed, is operated by pair trawling, where two boats simultaneously tow a demersal trawl. One group of boats consists of a Tebune (the command boat), a trawler, and a fish carrier. Each boat searches for a school of whitebaits, and as soon as a school is spotted, all three boats assemble. The Tebune and trawler tow the net. Then, the carrier receives the captured fish and transports to the port to unload the catch for each trawl. In the Shizuoka Prefecture, the fishing season is from late March to mid-January of the following year, so fishing takes place almost all the year round except for the closed season. There is, however, a large fluctuation in daily hauls. Such a fluctuation is caused by diverse factors, such as the Kuroshio path and changes in the egg production [21], the actual cause is still unknown. Because of this fluctuation, precise understanding of the position and number of schools of whitebaits in the operation area and sharing such information with fishery workers would contribute to a more efficient operation. For this purpose, fishery workers request for the monitoring of fish migration into the fishing grounds and the development of an early notification system for fishing grounds.

In recent years, surveying with an echo sounder that estimates the spatial distribution of biomass has become popular [12]. An echo sounder transmits ultrasound waves in the water, receives soundwaves reflected by schools of fishes, and determines the density and position of such schools. Quantitative echo sounders and fisheries echo sounders are available. A quantitative echo sounder can quantitatively assess the biomass [1], so it is often used by government and university ships to survey resources. However, such ships are small in number and involve high survey cost, making it difficult to increase the number of surveys. In addition, such echo sounders are not installed on small fishing vessels that frequently sail because of high costs and the lack of space to store such detectors. On the other hand, smallest fishing vessels are equipped with fisheries echo sounders, but these detectors are different from quantitative echo sounders and are unable to quantitatively assess the biomass. In other words, quantitative echo sounders can quantitatively assess biomass but are not used on many ships, and surveys are not often performed. Thus, data can only be obtained for limited areas and time period. Contrarily, because fisheries echo sounders are used on many boats, larger amount of data can be obtained from much wider areas, but it is unclear whether such detectors can be used to measure biomass.

In the present study, we aimed to examine the relationship between the acoustic data for the same schools of fishes obtained with a fisheries echo sounder and the obtained with a quantitative echo sounder and verify the validity of the biomass assessment made with a fisheries echo sounder. In addition, we designed a system in which the data obtained with a fisheries echo sounder during regular operation are sent to the management server through a $3 G$ network [15]. Along with the positional information, fish school distribution information (fish school map) is obtained after data processing, and the map is provided only to the data providers (whitebait fishery workers). Whitebait fishery workers refer to this information and make decisions relevant to their operations and fishing grounds.

\section{Materials and methods}

We conducted a survey with two whitebait fishing boats along the shore of Mochimune, Suruga Ward, Shizuoka City, in the Shizuoka Prefecture (Fig. 1), where actual fishing operations were being conducted, on June 23, 2017. The survey was conducted with the Saimasamaru carrier ship equipped with a quantitative echo sounder ( 38 and $120 \mathrm{kHz}$; KSE300, Sonic Co., Ltd) and the Saimasamaru Tebune equipped with a fisheries echo sounder (50 and 200 kHz; FCV1500L, Furuno Electric Co., Ltd.) (Table 1). The two ships searched for schools of whitebaits, and when a school was found, two ships assembled and performed the acoustic echo, which was 


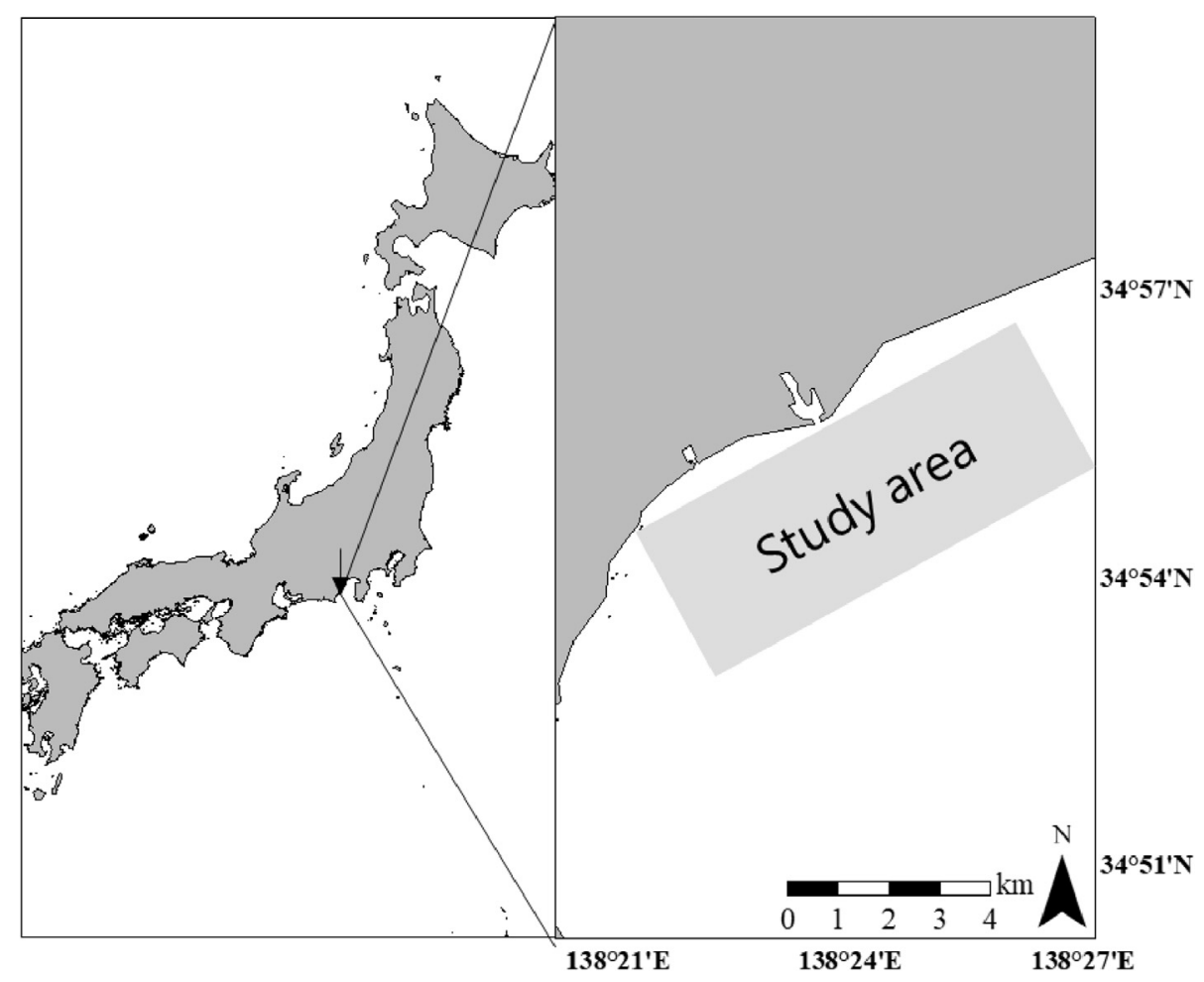

Fig. 1. The study area in Mochimune, Suruga Ward, Shizuoka City in Shizuoka Prefecture.

assumed to be the same school of whitebaits, using the quantitative and fisheries echo sounders. These measurement data were recorded on an external storage device along with the positional information obtained with GPS (Table 2). After the measurement, we sampled the fishes using a trawl with a kite (Table 3). The samples were fixed with $10 \%$ neutral buffered formalin on the ship and transported back to the laboratory. Subsequently, whitebait specimens were identified for each sampling point, and their length was measured with an electric nozzle. At sampling points with a large number of specimens, the whitebaits were selected after using a divider. The lengths of approximately 100 specimens were measured.

To analyze the acoustic intensity of the school of whitebaits obtained with the quantitative echo sounder, we used Echoview ver7.1. Generally, the indicators of biomass are the Volume backscattering

Table 1. Specification and Setting of quantitative echo sounder (KSE300) and fisheries echo sounder (FCV1500L).

\begin{tabular}{|c|c|c|c|c|}
\hline & \multicolumn{2}{|c|}{$\begin{array}{l}\text { Quantitative } \\
\text { echo sounder }\end{array}$} & \multicolumn{2}{|c|}{$\begin{array}{l}\text { Fisheries } \\
\text { echo sounder }\end{array}$} \\
\hline Beam type & \multicolumn{2}{|c|}{ Split beam } & \multicolumn{2}{|c|}{ Single beam } \\
\hline Frequency(kHZ) & 38 & 120 & 50 & 200 \\
\hline$-3 \mathrm{db}$ Beam width $\left(^{\circ}\right)$ & 8.4 & 8.2 & 28 & 8.5 \\
\hline
\end{tabular}

Table 2. Latitude and longitude of each survey site.

\begin{tabular}{llll}
\hline \multicolumn{2}{l}{ Survey point } & Lat. & Lon. \\
\hline 1 & Start point & 34.1955 & 138.3832 \\
& Finish point & 34.9159 & 138.3834 \\
2 & Start point & 34.9226 & 138.4038 \\
& Finish point & 34.9255 & 138.4074 \\
3 & Start point & 34.9237 & 138.4118 \\
& Finish point & 34.9233 & 138.4111 \\
4 & Start point & 34.9262 & 138.4022 \\
& Finish point & 34.9255 & 138.3984 \\
\hline
\end{tabular}

strength (SV) and the area backscattering strength (SA) [9]. When identifying schools of whitebaits from the acoustic data obtained with the quantitative echo sounder, a method that uses the difference between low and high frequencies is often employed [13]. Because whitebaits swim in a group by releasing the air from their bladders during daytime [22], there is a stronger echo in the higher frequency range than in the lower frequency range

Table 3. Number of samples, average length, standard deviation, mean TS in every survey point.

\begin{tabular}{lllll}
\hline Survey point & 1 & 2 & 3 & 4 \\
\hline number & 14 & 140 & 149 & 215 \\
average length(mm) & 16.75 & 18.55 & 17.08 & 22.12 \\
standard deviation & 7.11 & 4.12 & 3.11 & 3.53 \\
mean TS(dB) & -94 & -91.4 & -91.5 & -86.8 \\
\hline
\end{tabular}



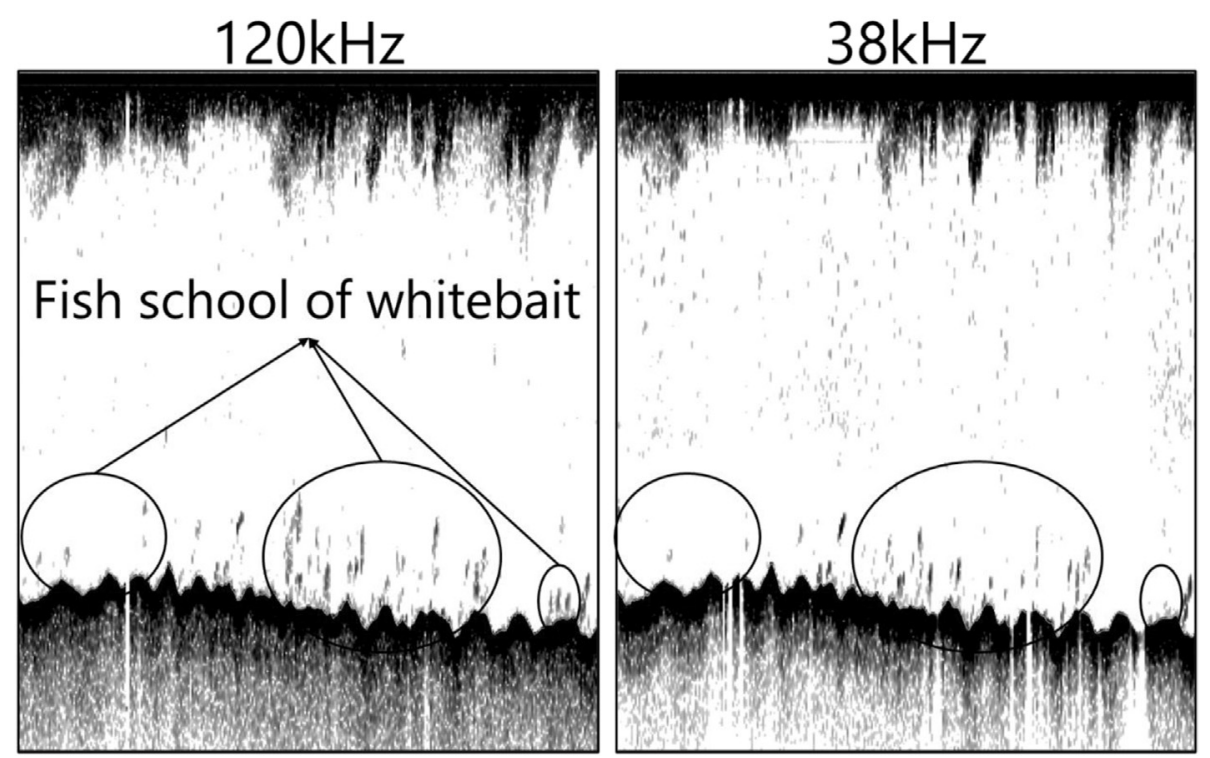

Fig. 2. Echogram of whitebait school obtained from quantitative echo sounder. Whitebaits have a stronger echo in the higher frequency range than in the lower frequency range.

[13] (Fig. 2). In the present study, we used this twofrequency method to identify schools of whitebaits. We set $\Delta S V=S V_{120 \mathrm{kHz}}-S V_{38 \mathrm{kHz}}$ with a threshold of $5 d B \leq \Delta S V \leq 30 d B$ to identify the schools of whitebaits [5]. In addition, when the SV value of an echo was weaker than $-75 \mathrm{~dB}$, it was excluded from the analysis as background noise. Echoes caused by bubbles created on the sea surface by the ship were manually removed [20]. The sea floor was set to be $0.2 \mathrm{~m}$ above the sea floor automatically detected by the echo sounder, and echoes determined to be originating from the sea floor were manually removed from the analytical target layers. The remaining echoes at $38 \mathrm{kHz}$ after the differential mask process were manually removed as they correspond to schools of fishes other than whitebaits [19]. The density of the target schools of whitebaits was obtained from the Target strength (TS). For determining the TS, we used the average length of the whitebaits collected at each location with the trawler with a kite and substituted it into the following TS formula [5].

$T S_{\text {avg }}=60.9 \log _{10} L-107.4$

This step was followed by dividing the SA calculated from the quantitative echo sounder with the mean TS of the net sampling at each location to calculate the biomass.

The data obtained from the fisheries echo sounder were analyzed with whitebait school detection software (Environment Simulation Laboratory Co., Ltd.). This software automatically identifies schools of whitebait from the echo difference between two frequencies detected in the fisheries echo sounder and calculates the cross-sectional area of the schools [14]. By multiplying the time of echo and the speed of the ship, we obtained the echo distance in the horizontal and vertical directions. The software calculates the SV and sets the SV difference between low and high frequencies SV. The SV difference threshold was automatically detected as the school of whitebaits. We set the difference threshold from $5 \mathrm{~dB}$ to $30 \mathrm{~dB}$ similar to the case for quantitative echo sounder and the whitebait threshold at $75 \mathrm{~dB}$ (Fig. 2). In addition, the software automatically removes data for the areas where the sea floor was not detected at a lower or higher frequency by the echo sounder. However, if there were bubbles near the surface and low and high frequencies were detected, these bubbles would be analyzed. Therefore, we did not consider in the analysis the echo in the top $5 \mathrm{~m}$ from surface.

For the same school of fish, the biomass calculated from the quantitative echo sounder and the crosssectional area of the schools of fishes obtained from the fisheries echo sounder were accumulated for each interval of 100, 500, 1,000, and $3000 \mathrm{~m}$, and the relationship between the biomass and the crosssectional area was statistically estimated using a generalized linear model (GLM). For visualization, we used R 3.4.2.

\section{Results}

\subsection{Net sampling and mean TS}

We performed sampling with a fishing trawler at four locations (Table 2). Survey point 1 did not have 
many samples (14 individual fishes), as $93 \%$ of the samples were Engraulis japonicus juveniles with an average length of $16.75 \mathrm{~mm}$ and TS of $-94 \mathrm{~dB}$ (Table 3). At survey point 2 , we selected 140 specimens and found that all of them were E. japonicus juveniles with an average length of $18.55 \mathrm{~mm}$ and TS of $-91.4 \mathrm{~dB}$ (Table 3). At survey point 3 , we selected 149 specimens from the total samples, and found that $95 \%$ of them were E. japonicus juveniles with a mean length of $17.08 \mathrm{~mm}$ and TS of $-91.5 \mathrm{~dB}$ (Table 3). At survey point 4 , there were a total of 215 specimens; all of them were E. japonicus juveniles with an average length of $22.12 \mathrm{~mm}$ and TS of $-86.8 \mathrm{~dB}$ (Table 3). Multiple comparisons of the mean sample length at each location using Tukey's test, indicated that only samples at survey point 4 showed significant difference from other samples. In addition, survey point 2 was different from other survey points, as the number of Mysidacea in the samples was extremely high. The wet weight of the formalin fixed specimens was $3.67 \mathrm{~g}$ for whitebaits and $28.14 \mathrm{~g}$ for Mysidacea.

\subsection{Relationship between the biomass obtained from the quantitative echo sounder and cross- sectional area of the schools of fishes calculated from the fisheries echo sounder}

The cross-sectional area of the fish schools calculated from the fisheries echo sounder and the biomass (number of fish) obtained from the quantitative echo sounder were accumulated for each sailing distance $(100,500,1,000$, and $3000 \mathrm{~m})$ and analyzed using the generalized linear model (Table 4). The result showed that when the sailing distance was 1000 or $3000 \mathrm{~m}$, there was a positive correlation between the cross-sectional area of the fish schools and biomass. However, such a correlation was not observed for the sailing distances of 100 and $500 \mathrm{~m}$ (Fig. 3).

Table 4. Statistical results of relationship between the biomass calculated from the quantitative echosounder and cross-sectional area of the schools of fishes obtained from the standard fish finder.

\begin{tabular}{|c|c|c|c|c|c|}
\hline \multicolumn{2}{|c|}{ Distance of each interval } & \multirow{2}{*}{$\begin{array}{l}\text { Estimate } \\
10.8225\end{array}$} & \multirow{2}{*}{$\begin{array}{l}\text { Std. } \\
\text { Error } \\
0.222\end{array}$} & \multirow{2}{*}{$\begin{array}{l}\mathrm{t} \\
\text { Value } \\
48.71\end{array}$} & \multirow{2}{*}{$\begin{array}{l}\mathrm{P} \\
\mathrm{P}<0.05\end{array}$} \\
\hline & & & & & \\
\hline & & & 0.0366 & 2.40 & \\
\hline \multirow[t]{2}{*}{$500 \mathrm{~m}$} & & & 75 & & \\
\hline & & & & & \\
\hline \multirow[t]{2}{*}{$1000 \mathrm{~m}$} & & 12. & 0.2381 & 52.48 & \\
\hline & & & & & \\
\hline \multirow[t]{2}{*}{$3000 \mathrm{~m}$} & & & & & \\
\hline & S(cross-sectiona & 0.008 & 0.0015 & 5.3 & $\mathrm{P}<0$. \\
\hline
\end{tabular}

The statistical models for the significant positive correlation between the cross-sectional area of the fish schools and biomass at the sailing distance of $3000 \mathrm{~m}$ as follows:

$\mathrm{y}=\exp (0.008204 \mathrm{x}+13.272783)$

Similarly, the statistical models for the significant positive correlation between cross-sectional area of fish schools and biomass when accumulated for each interval of $1000 \mathrm{~m}$ as follows:

$\mathrm{y}=\exp (0.17204 \mathrm{x}+12.496459)$

Therefore, at a distance of $1000 \mathrm{~m}$ or more, the distribution of whitebaits can be quantitatively monitored using a fisheries echo sounder. Thus, the distribution of whitebait resources can be quantitatively monitored over time using the fisheries echo sounder installed on fishing vessels.

\subsection{Developing a rapid notification system for fishing ground information}

To collect positional information and acoustic data from the fisheries echo sounder, we installed a device on the fishing vessels that sends information to the data management server using a 3G network. Thus, we designed a system that shares information on the distribution of fish schools (fish school maps) only with data providers (whitebait fishery workers). The data management server extracts the crosssectional area of whitebaits for each $1000 \mathrm{~m}$ horizontal distance in the received data and then generates the distribution information of the fish schools (fish school maps) based on the relationship between the cross-sectional area of the fish schools and biomass, as discussed above. The distribution information of the fish schools (fish school maps) is displayed as a three-stage heat map, where the highest biomass is shown in red, followed by green and blue. The information is updated every $15 \mathrm{~min}$ and can be viewed on devices such as a tablet on the fishing vessels in operation (Fig. 4).

\section{Discussion}

The present results showed a significant correlation between the cross-sectional area of the fish schools obtained from the fisheries echo sounder and the biomass obtained using the quantitative echo sounder. Using this formula, the fishing ground location and migration can be quantitatively evaluated using the data obtained from the fish detector during operation. Without conducting surveys using quantitative echo sounder on survey vessels, where the cost is high and the number of 


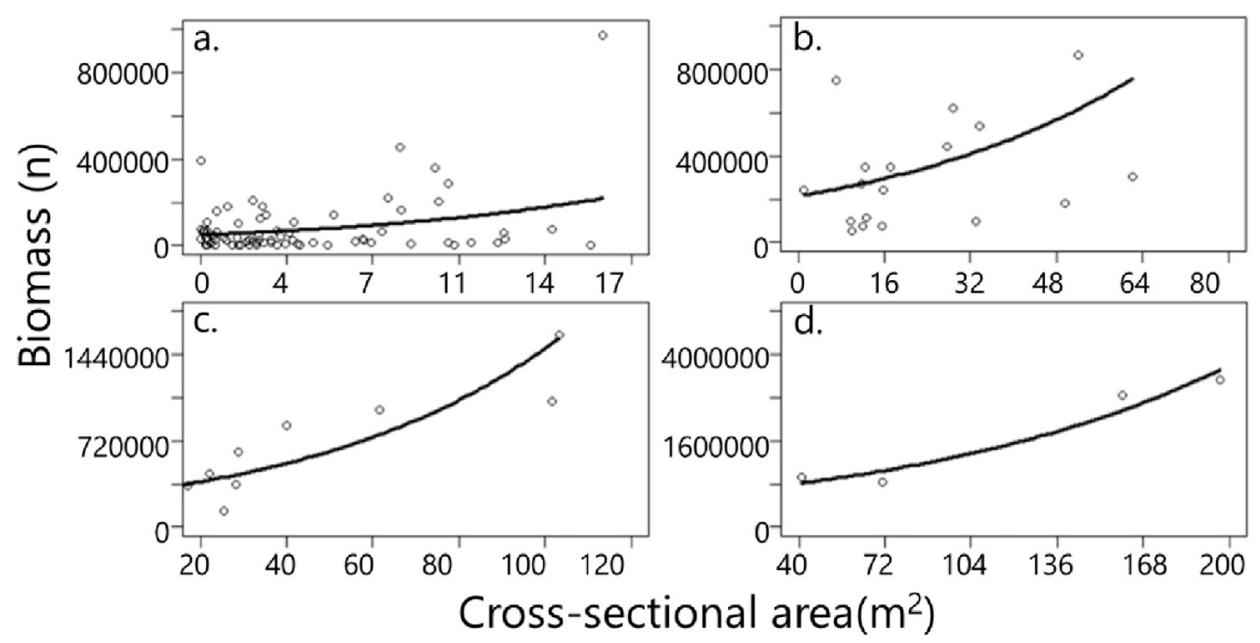

Fig. 3. Statistical results of relationship between the biomass $(n)$ calculated from the quantitative echosounder and cross-sectional area $\left(m^{2}\right)$ of the schools of fishes obtained from the standard fish finder in each interval. The solid line shows the estimated line of cross-sectional area. The open circles show the measured value between the biomass and cross-sectional area (a. $100 \mathrm{~m}, \mathrm{~b} .500 \mathrm{~m}, \mathrm{c.} 1000 \mathrm{~m}, \mathrm{~d} .3000 \mathrm{~m})$.

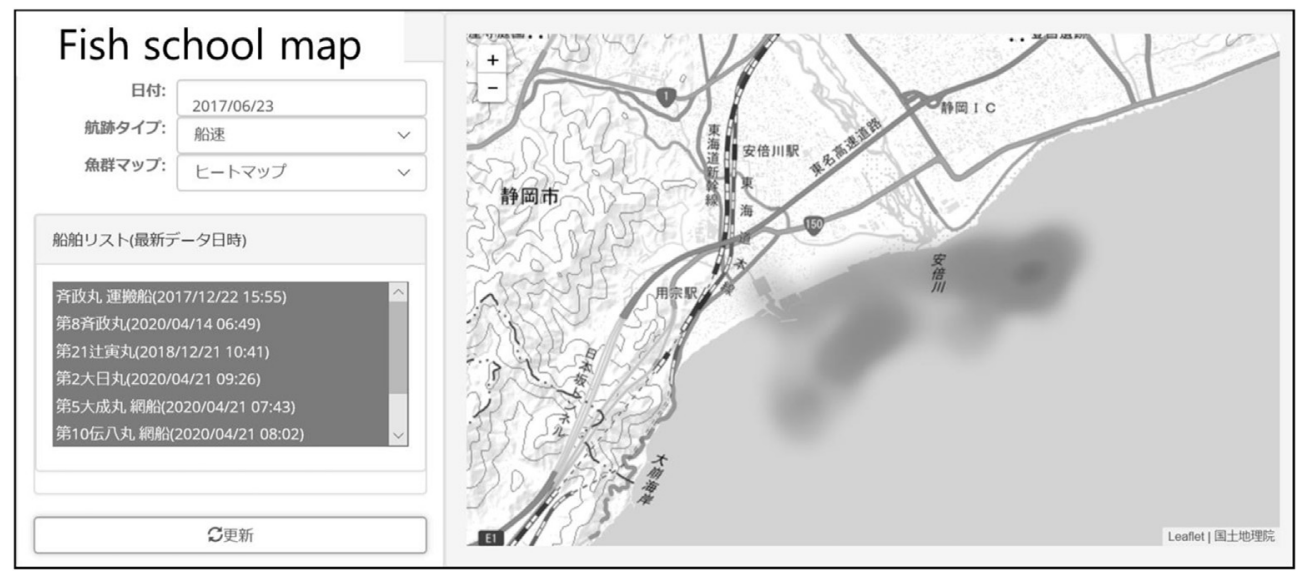

Fig. 4. The system which shares information on the distribution of fish schools (fish school maps) to data providers. The distribution information of the fish schools (fish school maps) is displayed with the different colors.

surveys is limited, data obtained using fisheries echo sounders that are regularly used by fishery workers can be used to assess the resource volumes.

However, the study was conducted during a stagnant period of daily hauls in the Mochimune coastal area [16], and schools of whitebaits were distributed as small patches. Hence, the positive correlation between the cross-sectional area of the fish schools and biomass was observed only when the sailing distance was $1000 \mathrm{~m}$ or more. If the size of schools of whitebaits is larger than that in the present survey (wider areas), the positive correlation between the cross-sectional area of the fish schools and biomass may be observed for a much shorter sailing distance. Depending on the amount of whitebait migration, the density of the schools of whitebait may change [17]. Thus, conducting surveys at various timings of migration may improve the accuracy of biomass estimation.
In the same study area, Mysidacea produced an acoustic echo similar to that generated by whitebaits [10], and the majority of samples collected at survey point 2 were Mysidacea. On the quantitative echo sounder, many echoes appeared to be generated from Mysidacea, but those can be separated with the frequency difference method. The echoes were mostly removed from the analytical image using the frequency difference process of the fisheries echo sounder, so we assume that the present analysis was successful in identifying the schools of whitebaits.

With regard to the rapid notification system on fishing ground information, the fish school density may change with migration; thus, the correlation between the cross-sectional area of the fish schools and biomass needs to be updated in future studies. At present, fishery workers can get visual information on understand the distance from the port to the fishing ground and biomass at the fishing ground 
based on the distribution information of the fish schools [15]. With further enhancements, the cost effectiveness (ratio of necessary cost for fisheries to the catch price) of the system can be improved.

\section{Acknowledgments}

This research received funding from the Hokkaido Bureau of Economy, Trade and Industry (Strategic basic technology advancement support project: Construction of a fishing ground information speed system to manage the fishing grounds in the coastal area by the contractor himself). We thank Masakazu Saito for navigating the research vessel and the preparation of research cruise. We also thank the Hokkaido University and Sonic Corporation for the support.

\section{References}

[1] Axenrot T, Hanson S. Seasonal dynamics in pelagic fish abundance in a Baltic Sea coastal area. Estuar Coast Shelf Sci 2004;60(4):541-7.

[2] Hasegawa M. The fishing ground formation of larval Japanese sardine and anchovy during spring in coastal waters of Shizuoka. Fish Biol Oceanograph Kuroshio 2014;15:19-27 [in Japanese].

[3] Hotta H. Japan's marine surveys and observations: present conditions and future prospects. Ocean Newslett 2014;332 [in Japanese].

[4] Itoh H. Feeding habits of larval and juvenile fish collected by a shore seine for shirasu (whitebait) in the inner part of Suruga Bay, central Japan. Bull Jpn Soc Fish Oceanogr 2009; 73(3):182-9 [in Japanese].

[5] Ito Y. Spatial estimation of larval Japanese anchovy distribution using acoustic method. Ph.D. Thesis. Japan, unpublished: Hokkaido University; 2011 (in Japanese).

[6] Katsukawa T, Iwasaki T, Makino K. Perspective of Japanese future fisheries II- Management and sustainable utilization of fisheries stocks. Nippon Suisan Gakkaishi 2010;76(2): 216-48 [in Japanese].

[7] Kinoshita I. Significance of the research of shirasu fishery grounds for resource and ecological study of pelagic fishes. Fish Biol Oceanograph Kuroshio 2006;7:3-12 [in Japanese].

[8] Kobayashi K. Construction of a fishing ground information bulletin system for fishermen to manage coastal fishing grounds themselves. Hokkaido Bureau of Economy. Trade Industr - Future Support Industr 2018. 5-3. (in Japanese).
[9] MacLennan ND, Fernandes GP, Dalen J. A consistent approach to definitions and symbols in fisheries acoustics. ICES (Int Counc Explor Sea) J Mar Sci 2002;59:365-9.

[10] Matsukura R, Sawada K, Abe K, Minami K, Nagashima H, Yonezaki S, et al. Comparison of measurements and model calculations of target strength of juvenile sandeel in Sendai Bay. Nippon Suisan Gakkaishi 2013;79(4):638-48 [in Japanese].

[11] Ministry of Agriculture. Forestry and fisheries (2010). Fisheries of Japan-FY2010. White paper on Fisheries; 2010. p. 18-9 (in Japanese).

[12] Miyake H, Ishida R, Muto T, Abe K, Mukai T, lida K. Acoustic assessment and distribution of spawning walleye Pollock Theragra chalcogramma in the Japan Sea off western Hokkaido using quantitative echo sounder. Sci Rep Hokkaido Fish Exp Stat 2001;59:11-24 [in Japanese].

[13] Miyashita K. Diurnal changes in acoustic frequency characteristics of Japanese anchovy Engraulis japonicus larvae. Nippon Suisan Gakkaishi 2002;68(4):564-8 [in Japanese].

[14] Miyashita K. Real time monitoring system for estimating juvenile Japanese anchovy distribution using a quantitative echo sounder system. Nippon Suisan Gakkaishi 2011;77: 300-3 [in Japanese].

[15] Miyashita K. Development and application of acoustic methods for monitoring fisheries resources and ecosystems. Nippon Suisan Gakkaishi 2019;85(3):294-6 [in Japanese].

[16] Nagakura Y. Characteristics of the 2017 shirasu fishery. Bull Shizuoka Prefect Res Instit Fish - Hekisui 2018;161 [in Japanese].

[17] Nagakura Y. Relationship between resource fluctuation of sardines and catch of Shirasu fishery. Bull Shizuoka Prefectural Res Instit Fish - Hekisui 2017;158 [in Japanese].

[18] Nakaizumi M. Case analysis of ICT utilization in improving management of fishing grounds. TUMSAT-OACIS Repository - Tokyo University of Marine Science and Technology; 2018. Research Paper 2018/3. (in Japanese).

[19] Sasaki T, Murayama T, Fukui K. Experiment of sufficient use of coastal anchovy juveniles' resource in the coastal waters off Shimane Prefecture. Report Shimane Prefect Fish Technol Cent 2009;2:65-70 [in Japanese].

[20] Shimmonds J, Maclennan D. Fisheries acoustis-theory and practice sedcond edtion. Massachusetts: Blackwell Publishing; 2006. p. 63-5.

[21] Suzuki T. Effects of the Kuroshio meander on shirasu fisheries in Shizuoka prefecture. Bull Shizuoka Prefectural Res Instit Fish - Hekisui 2006;114 (in Japanese).

[22] Uotani I. Diurnal changes of gas bladder and behavior of postlarvel anchovy and other related species. Bull Jpn Soc Sci Fish 1973;39(8):867-76 [in Japanese].

[23] Usui K, Kuniyasu T. Seasonal variation of proximate composition and change of freshness of shirasu in sagami bay. Bull Kanagawa Prefect Fish Res Instit 1997;2:85-93 [in Japanese]. 